This series is published by the

University of Oslo

Department of Economics

P. O.Box 1095 Blindern

N-0317 OSLO Norway

Telephone: + 4722855127

Fax: $\quad+4722855035$

Internet: http://www.oekonomi.uio.no

e-mail: $\quad$ econdep@econ.uio.no
In co-operation with

The Frisch Centre for Economic

Research

Gaustadalleén 21

N-0371 OSLO Norway

Telephone: $\quad$ +4722958820

Fax: $\quad+4722958825$

Internet: $\quad$ http://www.frisch.uio.no

e-mail: $\quad$ frisch@ frisch.uio.no

\section{Last 10 Memoranda}

\begin{tabular}{cl}
\hline No 14/08 & $\begin{array}{l}\text { Fedor Iskhakov } \\
\text { Pension reform in Norway: evidence from a structural dynamic model }\end{array}$ \\
\hline No 13/08 & $\begin{array}{l}\text { Eileen Fumagalli and Tore Nilssen } \\
\text { Waiting to Merge }\end{array}$ \\
\hline No 12/08 & $\begin{array}{l}\text { Pedro P. Barros, Steffen Hoernig and Tore Nilssen } \\
\text { Keeping both eyes wide open: The life of a competitive } \\
\text { authority among sectoral regulators }\end{array}$ \\
\hline No 11/08 & $\begin{array}{l}\text { Kari Furu, Dag Morten Dalen, Marilena Locatelli and Steinar Strøm } \\
\text { Generic substitution }\end{array}$ \\
\hline No 10/08 & $\begin{array}{l}\text { Reyer Gerlagh, Snorre Kverndokk and Knut Einar Rosendahl } \\
\text { Linking Environmental and Innovation Policy }\end{array}$ \\
\hline No 9/08 & $\begin{array}{l}\text { Steinar Strøm and Jon Vislie } \\
\text { A Discrete-Choice Model Approach to Optimal Congestion Charge }\end{array}$ \\
\hline No 8/08 & $\begin{array}{l}\text { M. I. Di Tomasso, Steinar Strøm and Erik Magnus Sæther } \\
\text { Nurses wanted. } \\
\text { Is the job too harsh or is the wage too low? }\end{array}$ \\
\hline No 7/08 & $\begin{array}{l}\text { Atle Seierstad } \\
\text { Existence of optimal nonanticipating controls } \\
\text { in piecewise deterministic control problems }\end{array}$ \\
\hline No 6/08 $5 / 08$ & $\begin{array}{l}\text { Halvor Mehlum and Karl Moene } \\
\text { King of the Hill } \\
\text { Positional Dynamics in Contests }\end{array}$ \\
\hline $\begin{array}{l}\text { Rotten Parents and Disciplined Children: } \\
\text { A Politico-Economic Theory of Public Expenditure and Debt }\end{array}$ \\
\hline
\end{tabular}

A complete list of this memo-series is available in a PDF® format at: http://www.oekonomi.uio.no/memo/ 


\title{
I Don't Want to Hear About it: Rational Ignorance among Duty-Oriented Consumers
}

\author{
Karine Nyborg*
}

July 10, 2008

\begin{abstract}
Individuals with a preference for keeping moral obligations may dislike learning that voluntary contributions are socially valuable: Such information can trigger unpleasant feelings of cognitive dissonance. I show that if initial beliefs about the social value of contributions are sufficiently low, duty-oriented consumers are willing to pay to avoid information. Attitude campaigns can increase contributions from such consumers by providing them with unwanted information. Consequentialist warm glow types with low initial beliefs, however, will seek low-cost information on their own initiative; thus, campaigns will have less effects for such consumers.
\end{abstract}

JEL codes: D11, D62, D64, D89, H41, Q21.

Keywords: Voluntary contributions, public goods, responsibility, altruism, information campaigns, cognitive dissonance.

${ }^{*}$ Department of Economics, University of Oslo, P.O.Box 1095 Blindern, NO-0317 Oslo, Norway. E-mail: karine.nyborg@econ.uio.no. Phone: +4722857283, fax: +4722855035. This research was partly conducted while I was employed by the Ragnar Frisch Centre for Economic Research, and partly during my participation in the project "Environmental economics: policy instruments, technology development, and international cooperation" at the Centre for Advanced Study (CAS) at the Norwegian Academy of Science and Letters in 2005. I am grateful to the Research Council of Norway for funding through the SAMSTEMT/RENERGI programmes, and to the Frisch Center and CAS for their financial, administrative and professional support. Thanks also to Geir Asheim, Kjell Arne Brekke, Anniken Greve, Tore Helstrup and Michael Rauscher for valuable comments and discussions. 
Innocence is ignorance. (Kierkegaard, 1844)

\section{Introduction}

Voluntary contributions to public goods are frequently observed in everyday life: People contribute to charities, volunteer in schools and hospitals, recycle their household waste, and pay higher prices for eco-labelled or fairtrade-labelled goods.

Public authorities try to stimulate such voluntary contributions through various means, including economic incentives such as tax exemptions for charitable contributions. Attitude and/or information campaigns represent another type of instrument. However, while such campaigns seems popular among policy makers, it is not evident, from an economists' perspective, why they might be expected to increase contributions. The present paper proposes one possible explanation for this.

The traditional Homo Oeconomicus model can hardly explain the observed amount of voluntary contributions to public goods. ${ }^{1}$ Consequently, economists have proposed a variety of alternative models. ${ }^{2}$ In the applied public economics literature, the most popular one seems to be the impure altruism model of Andreoni (1990). Andreoni assumed that consumers have preferences for a private good, the "warm glow of giving", which is increasing in the consumer's own contribution. The impure altruism model is able, in a simple and elegant way, to explain substantial voluntary contributions to public goods. Nevertheless, as information as such plays no role in the standard version of the impure altruism model, it cannot readily explain why decision-makers would spend money on campaigns informing people about the social value of their potential contributions.

It seems intuitively plausible that individuals' willingness to contribute depends on the social value of contributions (or beliefs about this). Below, I will formalize two reasons why this may be so. First, if contributions are thought to be more socially valuable, this may produce stronger feelings of moral obligation. I will call this duty-orientation. Second, warm glow may be a function of the consequences of one's contribution (or rather, beliefs about this), rather than the contribution as such. I will call this consequentialist warm glow. Both arguments imply that contributions are increasing in their believed marginal social value. I will show, however, that predictions differ when it comes to seeking or avoiding information about the social value of contributions, and also regarding the effect of information campaigns. In an important class of situations, the duty-oriented is willing to pay to avoid getting information, while a person motivated by consequentialist warm glow is willing to pay to achieve it.

\footnotetext{
${ }^{1}$ See Andreoni's (1988). Andreoni's analysis of "pure altruism" is formally equivalent to the Homo Oeconomicus model where individuals have preferences for a private and a public good.

${ }^{2}$ For an overview, see Nyborg and Rege 2003; see also, e.g., Ellingsen and Johannesson 2008, Francois 2007, Benabou and Tirole 2006, Konow 2006, Brekke et al. 2003, Fehr and Schmidt 1999, Rabin 1993, Sugden 1984.
} 
Thus, when the cost of achieving information privately is sufficiently low, information campaigns will have no effect on the latter type of consumer, since they would have sought information anyway. Duty-oriented individuals, however, may increase their contributions as a result of receiving unwanted information. If moral responsibility is a burden, and this burden is to some extent endogenous to the individual, he has an incentive to avoid situations which might face him with a heavier responsibility.

Recent experimental studies indicate that many people do seem to avoid situations associated with a moral responsibility. Lazear et al. (2005) conducted a dictator game experiment in which subjects, in a first round, were asked to divide 10 USD between themselves and another participant, being free to take everything for themselves if they so wished. In a second round, the same subjects were given the choice between playing exactly the same game once more or to "pass", where the latter meant receiving 10 USD without the opportunity to share. The majority of subjects chose to share at least some of their endowment in the first round. However, in the second round, most subjects - including many who had given the recipient a substantial share in the first round, thus apparently having preferences for sharing - chose to pass, avoiding the sharing option altogether. Consequently, the option not to be faced with the sharing environment at all reduced total contributions to about half of the first round level. In subsequent rounds, the researchers introduced a strictly positive cost of opting out; still, a substantial share of subjects chose to pass.

While this study did not specifically consider information, Dana el al. (2004) did. They found that in a binary version of the dictator game, most subjects choosing between a "fair" $(5,5)$ and an "unfair" $(6,1)$ outcome chose the fair alternative. ${ }^{3}$ In another treatment, the researchers made recipients' payoff uncertain, so that payoffs were either $(5,5)$ and $(6,1)$, as above, or $(5,1)$ and $(6,5)$, with equal probability. However, this uncertainty could be resolved by dictators at no cost, simply by pushing a button. In the uncertainty treatment, dictators behaved more selfishly, and only about half of them chose to resolve the uncertainty. While these findings may undoubtedly be explained in various ways, they are consistent with the view that people feel a heavier personal responsibility for others when their own impact on those others' situation is made unambiguously clear to them. Moreover, it is consistent with a hypothesis that the perceived responsibility to contribute, given that one's impact on others has been made clear, is stronger than the perceived obligation to seek such information.

Attitude campaigns aiming at increasing voluntary contributions often consist of two types of information. First, they typically emphasize the social importance of potential contributions (in terms of hard facts, such as the number of children who have lost their homes after an earthquake, or by other means, for example a photograph of one of those unhappy children). Second, campaigns often include information about efficient ways to contribute: where to place your recyclables, or how to donate money. While my discussion will focus on information about the marginal social value of donations, I will also briefly

\footnotetext{
${ }^{3}(x, y)$ denotes $x$ to the dictator and $y$ to the recipient.
} 
consider the second type of information.

Throughout the analysis, I will focus on internalized moral motivation, abstracting from social interaction effects such as conformism, reciprocity, or social rewards and sanctions from others. ${ }^{4}$ Further, I will limit my attention to situations where the consumer himself has no direct part in the social benefits he considers contributing to. The latter assumption implies that the consumer is paying for a credence good - a cognitive or psychological experience that is necessarily related to his beliefs about the action's consequences for others, since he will never experience for himself its true consequences. If no information is received from external sources, erroneous beliefs thus cannot be corrected, and the fact that beliefs are wrong will have no impact on the contributor's utility.

\section{The model}

Consider a population consisting of $n$ individuals, where individuals are identical except for a characteristic $\alpha_{i}$ determining $i$ 's benefits from a public good $G$. To fix ideas, assume that for every $i, \alpha_{i}$ equals either 0 or 1 , and let $\alpha_{i}=0$ mean that person $i$ is healthy, while $\alpha_{i}=1$ means that $i$ is an asthmatic. Individuals are sorted such that for $i=\{1, \ldots, m\}, \alpha_{i}=1$, while for $i=\{m+1, \ldots, n\}$, $\alpha_{i}=0$. To establish a benchmark case, let individuals have perfect information (later, this assumption will be relaxed).

Individual $i$ 's utility is given by (linear separability is assumed for the sake of simplicity):

$$
U_{i}=u\left(x_{i}\right)+\alpha_{i} G+S_{i}
$$

Here, $x_{i} \geq 0$ is $i$ 's consumption of private goods, $u$ is increasing and strictly concave, and $G$ is the level of a public good, which we may, for the purpose of illustration, think of as air quality. ${ }^{5} S_{i}$ corresponds to the warm glow of giving in the impure altruism model; I prefer, however, to think of $S_{i}$ as the individual's benefits of maintaining a good self-image (Brekke et al. 2003, Brekke and Nyborg 2008a, b). ${ }^{6}$ While every $i, j$ for whom $\alpha_{i}=\alpha_{j}$ have identical utility functions, the household production function for self-image $S_{i}$ will depend on the individual's motivation type. I will return to this below.

Person $i$ 's budget constraint is given by

$$
F=x_{i}+g_{i}
$$

\footnotetext{
${ }^{4}$ For studies incorporating such effects, see, for example, Rauscher (2006), Nyborg et al. (2006), Rege (2004), Hollander (1990), Sugden (1984).

${ }^{5}$ It seems natural to assume that $\lim _{G \rightarrow \infty} v(G)=0$, which would capture the idea that all else given, an asthmatic is never better off than a healty person. No such assumption is required for the formal analysis, however.

${ }^{6}$ Aronson et al. (2005, p.166), claim that "[f] or the past half-century, social psychologists have discovered that one of the most powerful determinants of human behavior stems from our need to preserve a stable, positive self-image". One explanation why giving may produce a warm glow is that giving improves, or confirms, the giver's positive view of himself. Previous economic analyses involving self-image and identity includes Ellingsen and Johannesson (2008), Akerlof and Kranton (2000, 2005), Benabou and Tirole (2002, 2003, 2006), Bruvoll and Nyborg (2004).
} 
where $F$ is an exogenous endowment. The assumption that each individual has the same endowment is not essential and is chosen for the sake of simplicity. Provision of the public good is determined by the sum of individual contributions in the following way:

$$
G=\beta \sum_{j=1}^{n} g_{j}
$$

where $\beta \geq 0$ measures how efficiently monetary contributions are transformed into increased supply of the public good. $\beta$ is, for now, exogenous and equal for everyone; I will return to the case of endogenous $\beta$ below. Further, I will assume that the public good level provided by others $(j \neq i)$ is considered exogenously fixed by $i$.

Since individuals' self-image may depend upon their beliefs about the social importance of their contributions, they will need to engage in normative evaluation of social states. Since normative disagreement is not the focus of the present paper, I will assume - again for simplicity - that every individual agrees that social welfare $W$ can be evaluated using the following simple social welfare function:

$$
W=\sum_{j=1}^{n}\left(u\left(x_{j}\right)+\alpha_{j} G\right)
$$

This corresponds to standard unweighted utiliarianism, except that benefits from self-image are not included. The latter is not important for the model's behavioral predictions, but simplifies the formal analysis considerably. ${ }^{7}$

In what follows, the marginal social value of $i$ 's contributions will be a central concept. By inserting from (1) - (3) into (4) and differentiating with respect to $g_{i}$, we get $^{8}$

$$
\frac{\partial W}{\partial g_{i}}=u^{\prime}\left(F-g_{i}\right)+m \beta
$$

which is the marginal net social value of contributions: The first term, $u^{\prime}\left(F-g_{i}\right)$, is the marginal social cost, while $m \beta$ is the gross marginal social gain. When I use the phrase "the social value of contributions" below, this refers to the gross marginal social benefit $m \beta$.

In the following, I will always assume that the individual $i$ whose behavior is considered is a healthy person, i.e. that $\alpha_{i}=0$. Again, this is not essential to the analysis, but since healthy individuals do not take part in the environmental benefits resulting from their contributions, this allows me to disregard possible "selfish" reasons to contribute, focusing exclusively on moral or altruistic motivation.

\footnotetext{
${ }^{7}$ See Brekke et al. (2003) and Brekke and Nyborg (2008a, b) for formal proofs of the equivalent claim in related models. One argument for not including self-image benefits is that the satisfaction of doing good should not be included in the very definition of "good". On the other hand, I find it hard to claim that self-image benefits are somehow less "real" than other benefits. This is a philosophical question which may, indeed, matter in normative welfare analysis; my purpose here, however, is confined to positive behavioral analysis.

${ }^{8}$ Primes denote derivatives.
} 
Let us now turn to possible motivations for voluntary contributions, which can be formalized in terms of alternative household production functions (Stigler and Becker 1977) for a good self-image. I will consider four motivation types: Homo Oeconomicus, the standard warm glow model, the duty-oriented, and finally, the consequentialist warm glow model.

\section{Homo Oeconomicus}

The self-image function of Homo Oeconomicus is particularly simple:

$$
S_{i}^{H}=0 .
$$

The important thing is not, of course, the normalization to zero, but that self-image is exogenous. A healthy $\left(\alpha_{i}=0\right)$ Homo Oeconomicus will maximize his utility by contributing nothing. This result is rather trivial, hardly requiring formal proof: Contributions are costly, but yields no benefits whatsoever. If such a person receives information about the social value of his potential contribution, this will influence neither his behavior nor his utility: He simply doesn't care.

\section{The standard warm glow model}

The second motivation type corresponds to the "warm glow" motive in the standard version of Andreoni's (1990) impure altruism model. Thus, in the standard warm glow model, self-image is increasing in $i$ 's own contribution:

$$
S_{i}^{I}=\gamma\left(g_{i}\right)
$$

where $\gamma^{\prime}>0$ and $\gamma^{\prime \prime}<0$.

The first order condition for utility maximization of a healthy person of this type, assuming an interior solution, is

$$
u^{\prime}\left(F-g_{i}\right)=\gamma^{\prime}\left(g_{i}\right)
$$

i.e., he contributes until his marginal benefit of consumption equals the marginal warm glow. Contributions are strictly positive provided that $u^{\prime}(F)<\gamma^{\prime}(0)$; otherwise, contributions are zero. Obviously, none of this depends upon the number of asthmathics $m$, nor on the efficiency of contributions in producing a higher public good supply, $\beta$. For the this type, thus, neither behavior nor utility will be affected by these variables.

\section{Duty-orientation}

\subsection{The full information case}

If moral obligation is a burden, information avoidance might be a means to keep that burden light. Let me now turn to the model of duty-orientation, which will 
be largely based upon the model of moral motivation proposed by Brekke et al. (2003).

The duty-oriented assesses his self-image by comparing his actual contributions to what he thinks he ought to have contributed. Self-image for this type of individual can thus be specified by some function $f\left(g_{i}, g_{i}^{*}\right)$, where $g_{i}^{*} \geq 0$ is $i$ 's perception of the morally ideal contribution; that is, a value for which increased contributions cannot further improve self-image. For simplicity, I will use the following: ${ }^{9}$

$$
S_{i}^{D}=-a\left(g_{i}-g_{i}^{*}\right)^{2}
$$

where $a>0$. The ideal contribution $g_{i}^{*}$ can be regarded as representing $i$ 's perceived moral responsibility. If $i$ contributes less than he thinks he should, his self-image will be lower than its maximum. ${ }^{10}$ Similar assumptions can be found in Woodward and Warren-Boulton (1984), Brekke et al. (2003), Bruvoll and Nyborg (2004), Konow (2006) and Cappelen et al. (2007). This self-image function is closely linked to the concept of cognitive dissonance (Festinger 1957); the idea that people experience an unpleasant feeling when discrepancies arise between the values they hold and the actions they take. Aronson et al. (2005) define cognitive dissonance as "a drive or feeling of discomfort, originally defined as being caused by holding two or more inconsistent cognitions and subsequently defined as being caused by performing an action that is discrepant from one's customary, typically positive self-conception" (p.166). ${ }^{11}$

If $a=0$, duty-orientation would be equivalent to Homo Oeconomicus. If $a>0$ while $g_{i}^{*}$ were exogenously fixed, and the analysis were restricted to $g_{i} \leq g_{i}^{*}$, duty-orientation would be equivalent to the standard warm glow model. The interesting distinction occurs when we take into account that $g_{i}^{*}$ may be endogenous.

In the analysis below, $g_{i}^{*}$ will be an increasing function of the social value of contributions. Several ethical principles would yield such a relationship. Some people may think, for example, that they should ideally contribute as long as their contribution strictly increases social welfare. While this principle might produce a rather heavy individual moral obligation, it would obviously yield a positive relationship between $g_{i}^{*}$ and $m \beta$.

Here, I will apply the approach of Brekke et al. (2003), who defined $g_{i}^{*}$ as that contribution which would maximize social welfare if chosen by everyone. This can be regarded as inspired by the Golden Rule, or Kant's Categorical

\footnotetext{
${ }^{9}$ Appendix A discusses the robustness of main properties of $S_{i}^{D}$ for alternative specifications of $f\left(g_{i}, g_{i}^{*}\right)$.

${ }^{10}$ One may dispute whether it is reasonable to assume that self-image decline if $i$ contributes too much. However, since the individual will never want to contribute too much anyway, this is not important.

${ }^{11}$ For economic analyses of cognitive dissonance, see e.g. Akerlof and Dickens (1982), Konow (2000), Oxoby (2004). Note that cognitive dissonance is not only related to moral issues : "Most of us have a need to see ourselves as reasonable, moral, and smart. When we are confronted with information implying that we may have behaved in ways that are irrational, immoral, or stupid, we experience a good deal of discomfort" (Aronson et al. 2005, p. 166). Akerlof and Dickens (1982) focus on the need to feel "reasonable" and "smart".
} 
Imperative, and is a version of what was called "a principle of rational commitment" by Harsanyi (1980) and "the principle of unconditional commitment" by Sugden (1984): $i$ should contribute at least as much as she would prefer everybody else to contribute. Although my main results from the duty-orientation model arise from the positive relationship between $g_{i}^{*}$ and $m \beta$, and are thus not essentially dependent on the particular ethical origin of this relationship assumed here, I find that the formal expressions resulting from the application of a specific ethical principle do provide some extra intuition.

Thus, let $g_{i}^{*}=\arg \max _{g_{i}} W$, subject to $g_{i}=g_{j}$ for every $j \in\{1, \ldots, n\}$, where $W$ is given by eq. (4). Solving this maximization problem yields the following first order condition for an interior solution:

$$
m \beta=u^{\prime}
$$

This corresponds to the usual Samuelsonian condition for optimal provision of a public good: the marginal social value of increased public good supply should, in optimum, equal its marginal cost. ${ }^{12}$

The ideal contribution $g_{i}^{*}$ is implicitly determined by eq. (8). If $g_{i}^{*}=0$, there is no moral obligation to contribute. The duty-oriented feels a responsibility to donate $\left(g_{i}^{*}>0\right)$ only if contributions are more socially valuable than private consumption, that is, if

$$
m \beta>u^{\prime}(F) .
$$

If (9) does not hold, the hypothetical welfare maximization problem has a corner solution, $g_{i}^{*}=0$. Differentiation of (8) with respect to $m \beta$ shows that for interior solutions, $g^{*}(m \beta)$ is strictly increasing in $m \beta$ :

$$
\frac{d g_{i}^{*}}{d(m \beta)}=\frac{1}{-u^{\prime \prime}}>0
$$

Consequently, the morally ideal contribution is a function $g_{i}^{*}=g^{*}(m \beta)$ of the marginal social value of contributions, such that whenever $m \beta \leq u^{\prime}(F)$, $g^{*}(m \beta)=0$, while for all $m \beta \geq u^{\prime}(F), d g_{i}^{*} / d(m \beta)=1 /-u^{\prime \prime}>0 .{ }^{13}$

Once the morally ideal contribution has been determined by the individual, he can decide how much to actually contribute. He does so by maximizing his utility with respect to $g_{i}$, taking $g^{*}(m \beta)$ as given, which yields the following first order condition for interior utility optimum:

$$
-2 a\left(g_{i}-g^{*}(m \beta)\right)=u^{\prime}
$$

The individual contributes until the marginal benefit in terms of an improved self-image (the left hand side) just equals its marginal cost in terms of forgone

\footnotetext{
${ }^{12}$ If individual endowments were not equal for all, this expression would $\operatorname{read} n m \beta=$ $\sum_{j=1}^{n} u^{\prime}$.

${ }^{13}$ Obviously, $g_{i}^{*}$ is also a function of income $F$; I will suppress this in the notation below, as $F$ will not be varied in the analysis. However, note that $g_{i}^{*} \in[0, F]$. If $u^{\prime}$ goes to infinity as consumption goes to zero, while $m \beta$ is finite, the individual will never feel obliged to give away absolutely everything, even for very high levels of $m \beta$.
} 
consumption benefits (the right hand side). Rearranging, this can be written

$$
g_{i}=g^{*}(m \beta)-\frac{u^{\prime}}{2 a}
$$

which shows clearly that, given an interior solution, the individual will always contribute strictly less than $g^{*}(m \beta) .{ }^{14}$

Again, we need to consider the possibility of a corner solution. If

$$
a\left[g^{*}(m \beta)^{2}-\left(g_{i}-g^{*}(m \beta)\right)^{2}\right] \leq u(F)-u\left(F-g_{i}\right)
$$

for every strictly positive $g_{i}$, the self-image gain from a contribution cannot outweigh the resulting consumption loss, and the individual maximizes his utility by contributing nothing. If $g^{*}(m \beta)=0,(13)$ obviously holds: with no moral obligation to contribute, there is no self-image loss from not contributing. Note, however, that (13) may hold even for low, but strictly positive levels of $g^{*}(m \beta)$. In such cases the individual contributes nothing, but does experience cognitive dissonance. Cognitive dissonance is only completely avoided when the social value of contributions is lower than its social cost, that is, low enough to yield $g^{*}(m \beta)=0$.

Using this, Proposition 1 below establishes that while the healthy, dutyoriented person's voluntary contribution is increasing in its social value $m \beta$, his utility is decreasing in $m \beta$.

Proposition 1 With perfect information, the following holds for the healthy duty-oriented individual: a) His contribution $g_{i}$ is weakly increasing in the marginal social value of contributions $m \beta$. The increase is strict if $a\left[g^{*}(m \beta)^{2}-\right.$ $\left.\left(g_{i}-g^{*}(m \beta)\right)^{2}\right] \geq u(F)-u\left(F-g_{i}\right)$ for some strictly positive $g_{i}$. b) His utility is weakly decreasing in the marginal social value of contributions $m \beta$. The decrease is strict whenever $m \beta>u^{\prime}(F)$.

Proof. See Appendix B.

Consequently, if a healthy, duty-oriented individual learns that the social importance of his contribution has increased, he will increase his contribution. But - unless his private consumption is even more socially valuable than contributions to the public good - his utility is strictly reduced: His burden of moral responsibility has become heavier.

\subsection{The case of limited information}

In this section, I will assume that individuals do not know the marginal social value of contributions $m \beta$. Most of us are aware that environmental degradation, hunger and injustice exist in abundance throughout the world; nevertheless, our knowledge about the precise character of each potential sub-problem, its

\footnotetext{
${ }^{14}$ See Brekke et al. (2003). Since $\partial S_{i} / \partial g_{i}=0$ when $g_{i}=g_{i}^{*}$, contributing $g_{i}^{*}$ could be optimal for the individuals only if $u^{\prime}=0$, which has been ruled out by assumption. That is, increasing $g_{i}$ up to or beyond $g_{i}^{*}$ would come at a strictly positive cost, but yield no extra self-image benefits.
} 
scope and severity, and whether and how something could be done to amend it, may be rather poor. I will interpret the model as a partial representation of a more complex world in which a large number of public goods and many groups of potential beneficiaries may exist, and use the model to study $i$ 's choice of whether to seek information about and/or contribute to one specific cause. ${ }^{15}$

If an individual does not suspect at all that increased provision of the specific public good $G$ might benefit someone, it seems hard to explain why he would even get the idea of seeking, or avoiding, information. Such complete ignorance is thus not the most interesting case to consider. Rather, by "ignorance" I will mean a state in which the individual has some notion that the social problem might possibly exist and that contributions might possibly be of value, but where he otherwise knows nothing about the number of beneficiaries $m$ (or more generally, the magnitude of the problem) nor the efficiency of potential contributions $\beta$. One may think of, for example, a substance which $i$ knows to be emitted into the air, but which he has no further information about; he may simply know, on a general level, that some people react to some substances.

Imagine that there exists a verification agency which can provide perfect information about the true value of $m \beta$. Assume, moreover, that such information can be bought by the individual at a fixed cost $C$. Hence, the individual can be in one of two states; ignorant (uninformed) or informed. If informed, the individual knows $m \beta$ perfectly. ${ }^{16}$ If ignorant, the individual's belief about $m \beta$ is given by a subjective probability distribution $h(m \beta)$ with expectation $E(h(m \beta))=B_{i}^{0}$, where $B_{i}^{0}$ is $i$ 's uninformed prior belief.

The individual is now faced with the choice of whether to stay uninformed, denoted $\tau_{i}=0$, in which case he keeps his initial beliefs and pays no information cost, or whether to collect information, denoted $\tau_{i}=1$, in which case he pays $C$ and becomes perfectly informed about $m \beta$. This decision is made before the contribution decision. To incorporate the choice of whether to actively seek information, the budget constraint (2) must be replaced by

$$
F=c_{i}+g_{i}+\tau_{i} C
$$

If the individual chooses to become informed, this will bring us back to the perfect information case, and the contribution decision will be made as before (except that available income has been reduced by the amount $C$ ). If the individual decides to stay ignorant, I will assume that he applies the same self-image function as before (eq. 7), but that he now determines his moral obligation $g_{i}^{*}$ using the following adjusted principle: I should, ideally, contribute that amount which would maximize expected social welfare if contributed by everyone, given my subjective probability distribution $h(m \beta)$. That is, $g_{i}^{*}=$ $\arg \max _{g_{i}} E W$, subject to $g_{i}=g_{j}$ for every $j \in\{1, \ldots, n\}$, where $E W$ is given by

\footnotetext{
${ }^{15} \mathrm{I}$ will stick to the use of "healthy" to denote $\alpha_{i}=0$. This is less intuitively appealing when the problem at hand is ill known. However, its only function in the analysis is that we disregard "selfish" reasons for contributing, focusing on altruistic or moral motivation.

${ }^{16}$ Alternatively, one may assume that prior beliefs are updated in the direction of received information. This would not matter substantially; I stick to the simple assumptions.
} 


$$
\left.E W=\sum_{j=1}^{n} u\left(F-g_{i}\right)+B_{i}^{0} \sum_{j=1}^{n} g_{j}\right] .
$$

Solving this maximization problem yields the following first order condition for an interior solution:

$$
B_{i}^{0}=u^{\prime}
$$

which corresponds to eq. (8), except that $m \beta$ is now replaced by $B_{i}^{0}$. Thus, the ignorant individual will feel a responsibility to contribute (i.e., $g_{i}^{*}>0$ ) if

$$
B_{i}^{0}>u^{\prime}(F)
$$

Corresponding to the result obtained in Chapter 5.1, we have that

$$
\frac{d g_{i}^{*}}{d B_{i}^{0}}=\frac{1}{-u^{\prime \prime}}>0 .
$$

Consequently, $g_{i}^{*}$ can be written as a function of $i$ 's belief $B_{i}, g_{i}^{*}=g^{*}\left(B_{i}\right)$, where $g^{*}$ is the same function as in the previous section, and where $B_{i}=B_{i}^{0}$ if $\tau=0$ and $B_{i}=m \beta$ if $\tau=1$.

Now, will the duty-oriented seek or avoid information? Proposition 1 indicates that the duty-oriented would prefer not to receive information that $m \beta$ is higher than he thought. However, he does not expect new information to change his beliefs in any particular direction, since $E(h(m \beta))=B_{i}^{0}$.

Let us consider two cases separately. First, if the individual's belief $B_{i}^{0}$ is sufficiently high initially that $B_{i}^{0}>u^{\prime}(F)$, he feels a moral obligation to contribute even in the initial, ignorant state. New information might either add to (if $B_{i}^{0}<m \beta$ ) or ease (if $B_{i}^{0}>m \beta$ ) this burden of moral responsibility, and there is no reason to expect one to be more likely than the other. Thus, disregarding the cost $C$, there is no strong reason to believe that duty-oriented consumers would systematically avoid, nor seek, information in this case. ${ }^{17}$ If $C>0$, this provides, of course, an argument for not seeking information.

The most interesting case, however, is the case where initial beliefs about the social value of contributions are too low to produce a moral obligation in the initial situation; that is, when $B_{i}^{0}<u^{\prime}\left(F_{i}\right)$. In this case, $g_{i}^{*}\left(B_{i}^{0}\right)=0$. Since there is no obligation, the individual does not experience cognitive dissonance by not contributing. His utility if staying ignorant $\left(\tau_{i}=0\right)$ is, thus, simply given by $u(F)$; there is no self-image loss.

If he does seek information $\left(\tau_{i}=1\right)$, he may find that $m \beta$ is either higher or lower than $B_{i}^{0}$. If it is lower, he will still feel no obligation to contribute; his utility will then be given by $u(F-C)$, which is obviously strictly lower than $u(F)$ as long as $C>0$. If it turns out, on the other hand, that $m \beta>u^{\prime}\left(F_{i}\right)$,

\footnotetext{
${ }^{17}$ It is not necessarily the case that he is indifferent in expected utility terms, though, even if $C=0$; this depends on the curvature of $U_{i}$ as a function of $m \beta$ and on the subjective probability distribution $h(m \beta)$. Depending on the details of $u\left(x_{i}\right)$ and $h(m \beta)$, the dutyoriented consumer with high prior beliefs may seek information, avoid information, or be indifferent. For details, see Appendix B.
} 
he will feel obliged to contribute. He will still not necessarily contribute (see eq. (17)); but whether he does contribute or not, he will now (in addition to having paid the cost $C$ ), face $\operatorname{cognitive}$ dissonance. His utility will now be given by $u\left(F-C-g_{i}\right)-a\left(g_{i}-g_{i}^{*}(m \beta)\right)^{2}$, where $g_{i}^{*}(m \beta)>0$ and $g_{i} \geq 0$. It should be immediately clear that this is always strictly less than $u(F)$, his utility if not collecting information. Moreover, it is strictly less than $u(F)$ even if information were costless $(C=0)$. Hence, if initial beliefs are sufficiently low, getting more information can do the duty-oriented individual no good, and may well do him harm. This leads directly to the next Proposition:

Proposition 2 If $B_{i}^{0} \leq u^{\prime}\left(F_{i}\right)$, there exists a strictly negative information cost $\underline{C}<0$ such that for every information cost $C>\underline{C}$, the healthy duty-oriented consumer strictly prefers not to acquire information.

In other words, in this case, the consumer is willing to pay a strictly positive amount to avoid information.

The question remains, of course, how plausible (or common) it is that $B_{i}^{0}<$ $u^{\prime}\left(F_{i}\right)$. I do not know this, and I certainly have no intention of claiming that $B_{i}^{0}$ is always low. As a purely subjective judgement, however, I do find it rather natural that a person would not feel obliged to contribute to a causes he knows next to nothing about. Moreover, research within both social psychology and economics has established that self-serving bias in belief formation is common (see, e.g., Aronson et al. 2005 pp.119-122, Konow 2000). While the analysis so far has not involved any assumptions of self-serving bias in belief formation, it may be reasonable to expect a certain self-serving bias in the formation of the uninformed prior belief $B_{i}^{0}$, since this belief is, after all, not well-founded anyway. If such self-serving bias is present, it definitely increases the relevance of the low initial belief case.

\section{The consequentialist warm glow model}

It happens, though, that one encounters people who seem to be extremely eager in collecting information about the world's misery. Although this might be consistent with duty-oriented individuals with high initial beliefs (see footnote 17), the intuition does not quite seem to match. Let me, therefore, briefly consider a fourth motivation type, namely the consequentialist warm glow model.

In Andreoni's (1990) original model of impure altruism, there was no explicit distinction between a person's contribution and the consequences of this contribution. However, when there is a such distinction, people may care about the social importance of their contributions rather than the actual amount that they contributed. The consequentialist warm glow type, thus, has a preference to be important to others (see also Brekke and Nyborg, 2008). Like the standard warm glow type, he cares about his own role in public good provision; unlike the standard warm glow type, however, he also cares about consequences.

For this type, too, increased beliefs about the social value of contributions will increase contribution levels. Nevertheless, information campaigns will not 
necessarily have any effect for this type: If information on the social benefits of contributions are available at no or low cost, this type will, in contrast to the duty-oriented, have an incentive to seek this information himself. Thus, unless information is too costly to obtain on one's own initiative, information campaigns would be redundant within the consequentialist warm glow model.

I will assume that consequentialist warm glow type evaluates his own importance by asking himself: "If I contribute $g_{i}$ rather than nothing, all else given, how much will others' welfare increase?" Thus, in the perfect information case, we can write

$$
S_{i}^{C}=\mu\left(\Delta W_{-i}\right)
$$

where $\mu$ is an increasing and concave function, and $\Delta W_{-i}$ is the effect on others' welfare of $i$ 's contribution. If $W_{-i}\left(g_{1}, \ldots, g_{n}, m \beta\right)$ is defined as $\left[W-u\left(x_{i}\right)-\alpha_{i} G\right]$ given that contributions equal $\left\{g_{1}, \ldots, g_{n}\right\}$ and the social value of contributions is $m \beta, \Delta W_{-i}$ can be specified as

$$
\Delta W_{-i}=W_{-i}\left(g_{1}^{0}, \ldots, g_{i}, \ldots, g_{n}^{0}, m \beta\right)-W_{-i}\left(g_{1}^{0}, \ldots, 0, \ldots, g_{n}^{0}, m \beta\right)
$$

that is, $\Delta W_{-i}$ is the increase in others' welfare when $i$ 's contribution equals $g_{i} \geq 0$ rather than 0 , subject to the restriction that everybody else's behavior is kept fixed. ${ }^{18}$ Inserting from (1) - (4) in (19) then yields

$$
S_{i}^{C}=\mu\left(m \beta g_{i}\right)
$$

That is, the self-image of the consequentialist warm glow type is an increasing function of the social value of his contribution $m \beta g_{i}$. Utility maximization with respect to $g_{i}$ now yields the following first order condition for an interior maximum:

$$
u^{\prime}=m \beta \mu^{\prime}
$$

The healthy person contributes until his marginal utility of consumption equals the marginal self-image benefits, determined by the importance of his contribution to others. If

$$
u^{\prime}(F)>m \beta \mu^{\prime}(0),
$$

utility reaches its maximum in the corner solution $g_{i}=0$; in this case, the marginal warm glow is not strong enough to justify any loss of consumption.

If the social value of a potential contribution increases, this makes the individual - for any given strictly positive contribution level - more important to others than he was before. This increases both his contribution and his utility:

Proposition 3 With perfect information, the following holds for the healthy consequentialist warm glow type: a) His contribution $g_{i}$ is weakly increasing in the marginal social value of contributions $m \beta$. The increase is strict if $u^{\prime}\left(F_{i}\right)<$ $m \beta \mu^{\prime}(0)$. b) His utility is weakly increasing in the marginal social value of contributions $m \beta$. The increase is strict if $u^{\prime}\left(F_{i}\right)<m \beta \mu^{\prime}(0)$.

\footnotetext{
${ }^{18}$ A superscript 0 denotes a variable's value in the initial situation.
} 
Proof. See Appendix B.

In particular, as more people (others, to be sure) become asthma patients, the utility of the consequentialist warm glow type increases, as this improves his opportunities to be important to others. This may, of course, appear somewhat absurd; it would, however, explain the kind of eager information-seeking activites. ${ }^{19}$

What if information is imperfect? Assume that the ignorant consumer's self-image is given by

$$
S_{i}^{C}=\mu\left[E \Delta W_{-i}\right]
$$

where

$$
E \Delta W_{-i}=E\left[W_{-i}\left(g_{1}^{0}, \ldots, g_{i}, \ldots, g_{n}^{0}, m \beta\right)-W_{-i}\left(g_{1}^{0}, \ldots, 0, \ldots, g_{n}^{0}, m \beta\right)\right] .
$$

Inserting from (1) - (4) then yields $E \Delta W_{-i}=B_{i}^{0} g_{i}$. Consequently,

$$
S_{i}^{C}=\mu\left(B_{i}^{0} g_{i}\right) .
$$

Consider first the case where $u^{\prime}(F)<B_{i}^{0} \mu^{\prime}(0)$, that is, beliefs are sufficiently high to merit contributions in the ignorant state. Like in the case of duty-orientation, seeking information could then reveal that $m \beta$ is either higher or lower than previously believed; and without further specification of the utility and subjective probability functions, the preferred information choice is indeterminate. ${ }^{20}$

Again, the interesting case is a case of low intial beliefs, namely the situation where $B_{i}^{0}$ is too low to merit contributions $\left(u^{\prime}(F)>B_{i}^{0} \mu^{\prime}(0)\right)$. The utility level if not seeking information will then be given by $u(F)$. If consequentialist warm glow type then seeks information $\left(\tau_{i}=1\right)$, he may find that $m \beta$ is higher or lower than $B_{i}^{0}$. If he finds that $m \beta<B_{i}^{0}$, he will still not contribute, and his utility is $u(F-C)$. If he finds, however, that

$$
u^{\prime}(F-C)<m \beta \mu^{\prime}(0)
$$

he will start contributing, and his utility will then be given by $u\left(F-g_{i}-\right.$ $C)+\mu\left(m \beta g_{i}\right)$. If $m \beta$ is sufficiently high, the increased self-image could more than compensate the cost $C$. Hence, there is a trade-off between the certain consumption loss caused by paying the information $\operatorname{cost} C$ and the possible discovery of a new possibility to be important to others.

If information is costless $(C=0)$, the healthy consequentialist warm glow type has nothing to lose by seeking information. It can never hurt him, since

\footnotetext{
${ }^{19}$ In Andreoni's (1990) impure altruism model, the individual was assumed to care both for his own contribution and for the public good supply as such. Similarly, one could, of course, design models where the individual cares not only about the effect of his own contribution, but also about others' welfare as such. Such a concern could partially or fully offset the "absurd" utility effect discussed above.

${ }^{20}$ For details on the curvature of $U_{i}$ as a function of $m \beta$, see Appendix B, proof of Proposition 3.
} 
if he has overestimated $m \beta$, his utility is left unchanged. It might benefit him, since an unexpected opportunity to be important to others may emerge. He would thus strictly prefer to receive free information. This leads directly to the following Proposition:

Proposition 4 If $u^{\prime}\left(F_{i}\right)>B_{i}^{0} \mu^{\prime}(0)$, there exists a strictly positive information cost $\bar{C}>0$ such that the healthy consequentialist warm glow type prefers to purchase information.

The interesting case is, again, a corner solution. Note, however, that this is a different kind of corner solution than in the duty-orientation case: The result in Proposition 2 were concerned with the case with no initial moral obligation, not the case of no initial contribution.

\section{Endogenous social value of contributions}

As mentioned in the introduction, attitude campaigns often include information about how to contribute: how much to clean one's recyclables, where to place them for collection, what product to avoid because it is especially environmenthostile, or which address or bank account number to use for charitable contributions.

Information of this type can increase the efficiency of contributions, thus changing $\beta$. This would imply that efficiency of contributions is an individualspecific parameter, whose value depends endogenously on whether the individual is informed. The production of the public good is now determined by

$$
G=\sum_{j=1}^{n} \beta_{j}\left(\tau_{j}\right) g_{j}
$$

which replaces equation (3), where $\beta_{j}\left(\tau_{j}\right)$ is the efficiency parameter of individual $j$ as a function of $j$ 's information choice.

To illustrate this, assume that $G$ cannot be provided directly by individuals, but must be channelled through a charitable organization. Say that there exists only one truly charitable organization with known efficiency $\tilde{\beta}$; with any other recipient of contributions, no public good supply will result. There exists $K \gg$ 1 bank accounts in society, and only one of these belongs to the charitable organization. ${ }^{21}$ Assume that $K$ is known.

For the sake of argument, assume now that $m$, the number of beneficiaries, is perfectly known, and that "being ignorant" simply means not knowing the bank account number of the charity. Contributing in a state of ignorance would then mean to pick a bank account number at random, yielding an expected efficiency of $\tilde{\beta} / K$. Hence, the individual's belief about the social value of his contribution can now be stated as

$$
B_{i}=\begin{array}{cc}
m \tilde{\beta} & \text { if } \tau_{i}=1 \\
m \tilde{\beta} / K & \text { if } \tau_{i}=0
\end{array}
$$

\footnotetext{
${ }^{21}$ Thanks to Kjell Arne Brekke for suggesting this interpretation.
} 
Consider first the case where $C=0$. Then, just as in the analysis above, the utility of the consequentialist warm glow type will be weakly higher for $\tau_{i}=$ 1 , and strictly higher if $g_{i}(m \tilde{\beta} / K)=0$ and $g_{i}(m \tilde{\beta})>0$. Knowing how to contribute increases his opportunity to be important to others. Thus, even if the information is associated with a strictly positive cost, he may be willing to seek it. If $g_{i}(m \tilde{\beta} / K)=0$ and $g_{i}(m \tilde{\beta})>0$ and the consequentialist warm glow type is initially ignorant, an attitude campaign informing him about how to contribute will increase both his contribution and his utility. If the cost of information $C$ is sufficiently low, however, he will, even in the absence of a campaign, have sought information on his own initiative, and a campaign will be redundant.

For the duty-oriented, however, the situation is again different. Let $C=0$. If $g^{*}(m \tilde{\beta} / K)=0$, while $g^{*}(m \tilde{\beta})>0$, the Duty-Oriented does not feel obliged to contribute under ignorance, but knows in advance that he will feel an obligation to contribute once he learns the right account number. His utility, thus, will strictly decrease once he becomes informed. In this case, the Duty-Oriented is willing to pay a strictly positive amount to avoid the information. For him, ignorance is a bliss: Knowing how to contribute leaves him with a heavier burden of moral responsibility. Nevertheless, if the charity, or others, succeed in providing him with the unwanted information, he will start contributing. Hence, although the Duty-Oriented does not want to listen, he will act upon the information if he does receive it; it is, consequently, in the charity's (or rather, the beneficiaries') interest to try to make him know.

\section{Discussion}

There is an important caveat to the above results. While I have assumed that self-image functions are determined by one's actual contributions and their social value, there has been no presumption that the choice of seeking or not seeking information contributes to one's self-image. An even more strongly duty-oriented person may feel a moral obligation to seek information, for example such that his self-image is impaired if he does not seek as much information as he would want everybody to seek. If so, it is less obvious that the dutyoriented individual would avoid information. ${ }^{22}$ The experiments by Lazear et al. (2004) and Dana et al. (2004), indicate, however, that a substantial number of people do avoid situations where they feel obligated to contribute, including avoidance of free information. Thus, many seem to adopt Kierkegaard's view: Innocence is ignorance.

A related argument to the one provided above could be made if individuals were informed initially, while recall or attention were costly. A feeling of obligation or warm glow may require that the social value of contributions is

\footnotetext{
${ }^{22} \mathrm{He}$ may still to some extent resist information, though: Recall that for interior solutions, a duty-oriented person will always contribute strictly less than $g^{*}(m \beta)$. In the same vein, he may seek less information than he ideally thinks he should. A formal analysis of this remains to be done.
} 
salient in the individual's mind at the time of decision-making. This, in turn, requires the provided information to be mentally processed, safely stored, and finally retrieved; all of which requires costly cognitive effort ${ }^{23}$. Such costly information processing would play much of the same role as the information cost $C$ in the analysis above. One difference is, however, that in the case of costly information processing, information or attitude campaigns need not necessarily provide new information; they could work simply by reminding people of knowledge they already possess, but would otherwise not have retrieved from memory. This may provide one explanation to the existence of attitude campaigns not providing factual information at all, but rather seeming to aim at reminding people of their moral obligations. For example, in the city of Oslo, central collection units for delivery of hazardous household waste are placed in easily visible places, decorated by large posters with a photograph of a naked infant and the following text: "You won't poison me, will you?" If information is less easily retrieved by those to whom it implies a burden of responsibility, frequent reminders could be an unpleasant, but effective way to keep obligations salient in the duty-oriented's mind.

Social psycologists have pointed out that cognitive dissonance can potentially be reduced by changing one's ideals rather than by changing actual behavior (see, e.g., Aronson et al. 2005). It is well documented that views of fairness tend to be self-serving (e.g., Konow 2000). Similarly, self-serving interpretation of facts seems to be very common (see, e.g., Aronson et al. 2005, Ch.4); this is presumably particularly important for non-verifiable factual information, such as accounts of others' utility. In the above analysis, the principle determining the duty-oriented's moral obligations was assumed fixed. For simplicity, I also assumed that asthmatics' marginal utility of $G$ was perfectly known. Nevertheless, if the government or others tried to impose heavy moral obligations on individuals, it is certainly conceivable that those individuals would respond by changing their moral principles or beliefs.

\section{Concluding remarks}

If moral responsibility is a burden to the individual, and if, moreover, this burden is to some extent endogenous to him, there is an incentive to avoid situations which may face the individual with a heavier burden of responsibility. Economic analysis of voluntary contributions needs to take this into account. Although a duty-oriented consumer might contribute a lot the moment he has accepted a personal responsibility for an issue, he might go to quite some lengths to avoid being faced with that responsibility.

I have shown that if prior beliefs about the social value of contributions are sufficiently small, duty-oriented consumers are willing to pay a strictly positive amount to avoid receiving accurate information, while consequentialist warm

\footnotetext{
${ }^{23}$ For discussions of the psychology of attention and memory, see, for example, Styles (2005) or Magnussen and Helstrup (2007).
} 
glow types are willing to purchase information at a strictly positive cost. Attitude and information campaigns can increase contributions simply by informing duty-oriented consumers about social needs they would have preferred to be ignorant about. For consequentialist warm glow types, campaigns may have less effect, since this type is more likely to seek information on his own initiative; however, if information is costly, campaigns may increase contributions from this type of consumer too.

Does this mean that attitude campaigns should be used more extensively, as a cheap means to increase the provision of public goods? Perhaps, but the answer is not straightforward. The outcome of a welfare analysis would depend on the share of different motivation types in the population, and, more fundamentally, on whether or not self-image benefits are included in the social welfare function. If self-image benefits are included, cognitive dissonance must

be counted as a social cost, and there is no guarantee that the extra burden of moral responsibility caused by an attitude campaign is outweighted by the social benefits of increased contributions. Since my scope has been positive rather than normative analysis, I will not pursue this issue further here.

\section{References}

[1] Akerlof, G. A., and W. T. Dickens (1982): The Economic Consequences of Cognitive Dissonance, American Economic Review 72 (3), 307-319.

[2] Akerlof, G. A., and R. E. Kranton (2000): Economics and Identity, Quarterly Journal of Economics 115(3), 715-53.

[3] Akerlof, G. A., and R. E. Kranton (2005): Identity and the Economics of Organizations, Journal of Economic Perspectives 19(1), 9-32.

[4] Andreoni, J. (1988): Privately Provided Public Goods in a Large Economy: The Limits of Altruism, Journal of Public Economics 35(1), 57-73.

[5] Andreoni, J. (1990): Impure Altruism and Donations to Public Goods: A Theory of Warm-Glow Giving, Economic Journal 100(401), 464-477.

[6] Aronson, E., T.D. Wilson, and R.M. Akert (2005): Social Psychology. Fifth Edition. New Jersey: Pearson Education International.

[7] Benabou, R., and J. Tirole (2002): Self-Confidence and Personal Motivation, Quarterly Journal of Economics 117 (3), 871-915.

[8] Benabou, R., and J. Tirole (2003): Intrinsic and Extrinsic Motivation, Review of Economic Studies 70 (3), 489-520.

[9] Benabou, R., and J. Tirole (2006): Incentives and Prosocial Behavior, American Economic Review 96 (5), 1652-1678.

[10] Brekke, K.A., K. Nyborg and S. Kverndokk (2003): An Economic Model of Moral Motivation, Journal of Public Economics 87(9-10), 1967-1983. 
[11] Brekke, K.A., and K. Nyborg (2008a): Attracting responsible employees: Green production as labor market screening, forthcoming in Resource and Energy Economics.

[12] Brekke, K.A., and K. Nyborg (2008b): Selfish Bakers, Caring Nurses? A Model of Work Motivation, HERO Working Paper 2008:1, Oslo: Health Economics Research Programme.

[13] Bruvoll, A., and K. Nyborg (2004): The Cold Shiver of Not Giving Enough: On the Social Cost of Recycling Campaigns, Land Economics 80(4), 539549 .

[14] Cappelen, A., A.D. Hole, E.Ø. Sørensen and B.Tungodden (2007): The Pluralism of Fairness Ideals: An Experimental Approach, American Economic Review 97 (3), 818-827.

[15] Dana, J., R.A. Weber, and J.X. Kuang (2004): Exploiting Moral Wriggle Room: Behavior Inconsistent with a Preference for Fair Outcomes. Unpublished note, Carnegie Mellon University.

[16] Ellingsen, T., and M. Johannesson (2008): Pride and Prejudice: The Human Side of Incentive Theory, American Economic Review, forthcoming.

[17] Fehr, E. and K.M. Schmidt (1999): A Theory of Fairness, Competition, and Cooperation, Quarterly Journal of Economics 114, 817-868.

[18] Festinger, L. (1957): A Theory of Cognitive Dissonance. Stanford, CA: Stanford University Press.

[19] Francois, P. (2007): Making a Difference, RAND Journal of Economics 38(3), 714-732.

[20] Harsanyi, J. (1980): Rule Utilitarianism, Rights, Obligations and the Theory of Rational Behavior, Theory and Decision 12, 115-133.

[21] Hollander, H. (1990): A Social Exchange Approach to Voluntary Cooperation, American Economic Review (80) 5, 1157-1167.

[22] Kierkegaard, Søren (1844): Begrebet Angest: en simpel psykologiskpaapegende Overveielse $i$ Retning af det dogmatiske Problem om Arvesynden. København (published under the pseudonym of Vigilius Haufniensis).

[23] Konow, J. (2000): Fair Shares: Accountability and Cognitive Dissonance in Allocation Decisions, American Economic Review 90 (4), 1072-1091.

[24] Konow, J. (2006): Mixed Feelings: Theories and Evidence of Warm Glow and Altruism, manuscript, http://ssrn.com/abstract $=980349$.

[25] Lazear, E.P., U. Malmendier, and R.A. Weber (2005): Sorting in Experiments with Application to Social Preferences, unpublished note, Carnegie Mellon University. 
[26] Magnussen, and T. Helstrup (eds.)(2007): Everyday Memory, New York: Psychology Press.

[27] Nyborg, K., R.B. Howarth, and K.A. Brekke (2006): Green Consumers and Public Policy: On Socially Contingent Moral Motivation, Resource and Energy Economics 28 (4), 351-366.

[28] Nyborg, K., and M. Rege (2003): Does Public Policy Crowd Out Private Contributions to Public Goods? Public Choice 115 (3), 397-418.

[29] Oxoby, R.J. (2004): Cognitive Dissonance, Status and Growth of the Underclass, Economic Journal 114, 727-749.

[30] Rabin, M (1993): Incorporating Fairness into Game Theory and Economics, American Economic Review 83, 1281-1302.

[31] Rauscher, M., 2006. "Voluntary Emission Reductions, Social Rewards, and Environmental Policy," CESifo Working Paper Series CESifo Working Paper No. 1838.

[32] Rege, M., 2004, Social Norms and Private Provision of Public Goods. Journal of Public Economic Theory 6(1), 65-77.

[33] Stigler, G.J, and G.S. Becker (1977): De Gustibus Non Est Disputandum, American Economic Review 67(2), 76-90.

[34] Styles, E.A. (2005): Attention, Perception and Memory. An Integrated Introduction. Hove and New York: Psychology Press.

[35] Sugden, R., 1984. Reciprocity: The Supply of Public Goods through Voluntary Contributions, Economic Journal 94, 772-787.

[36] Woodward, R.S. and F. Warren-Boulton (1984): Considering the effects of financial incentives and professional ethics on 'appropriate' medical care, Journal of Health Economics, 3 (3), 223-237.

\section{A Functional forms}

A more general specification of a duty-oriented consumer's self-image is

$$
S_{i}=f\left(g_{i}, g_{i}^{*}\right)
$$

where $f$ is continuous and differentiable, where for any given value of $g_{i}^{*}, f$ has its maximum at $g_{i}=g_{i}^{*}$; moreover, $f_{1}^{\prime}>0$ whenever $g_{i}>g_{i}^{*}, f_{1}^{\prime}=0$ when $g_{i}=g_{i}^{*}$, while $f_{1}^{\prime} \leq 0$ when $g_{i}>g_{i}^{*}$. Further, $f_{11}^{\prime \prime} \leq 0$ everywhere, $f_{2}^{\prime}<0$ when $g_{i}<g_{i}^{*}$, and $f_{2}^{\prime}=0$ when $g_{i}=g_{i}^{*}$. Some examples of functional forms satisfying the above requirements are $f^{I}\left(g_{i}, g_{i}^{*}\right)=-a\left(g-g_{i}^{*}\right)^{2}, f^{I I}\left(g_{i}, g_{i}^{*}\right)=-a \frac{\left(g-g_{i}^{*}\right)^{2}}{g_{i}^{*}}$ , and $f^{I I I}\left(g_{i}, g_{i}^{*}\right)=-a \frac{\left(g-g_{i}^{*}\right)^{2}}{\left(g_{i}^{*}\right)^{2}}$ (where $\left.a>0\right)$. Also, functions of the type 
$f^{I I I+k}\left(g_{i}, g_{i}^{*}\right)=\left\{f^{j}\left(g_{i}, g_{i}^{*}\right)\right.$ when $g_{i} \leq g_{i}^{*}$, and 0 when $\left.g_{i}>g_{i}^{*}\right\}$ satisfy the conditions, for all $k \in\{I, I I, I I I\}$ specified above.

In this general specificaton, we have that

$$
\frac{d g_{i}}{d g_{i}^{*}}=-\frac{f_{12}^{\prime \prime}}{f_{11}^{\prime \prime}+u^{\prime \prime}}
$$

Thus, the effect of $m \beta$ on contributions has the same sign as $f_{12}^{\prime \prime} \frac{d g_{i}^{*}}{d(m \beta)}$, provided that one is initially in an interior optimum. If the initial contribution is zero, contributions will increase if and only if the change implies that (13) ceases to hold; otherwise $g_{i}$ is unchanged. Moreover,

$$
\frac{d U_{i}}{d g_{i}^{*}}=\frac{f_{12}^{\prime \prime}\left[u^{\prime}+f_{1}^{\prime}\right]}{f_{11}^{\prime \prime}+u^{\prime \prime}}-f_{2}^{\prime}
$$

which is negative as long as $f_{12}^{\prime \prime}>0$, but may become positive if $f_{12}^{\prime \prime}<0$.

For $f^{I}\left(g_{i}, g_{i}^{*}\right)$ and $f^{I I}\left(g_{i}, g_{i}^{*}\right)$, it is always the case that $f_{12}^{\prime \prime}>0$. However, for $f^{I I I}\left(g_{i}, g_{i}^{*}\right)$, the cross derivative is given by

$$
\partial^{2} f^{I I I}\left(g_{i}, g^{*}\right) / \partial g_{i} \partial g_{i}^{*}=2 a \frac{\left(2 g_{i}-g_{i}^{*}\right)}{\left(g_{i}^{*}\right)^{3}}
$$

This is positive if

$$
g_{i}>\frac{1}{2} g_{i}^{*}
$$

Thus, with $f^{I I I}\left(g_{i}, g_{i}^{*}\right)$, a marginally increased ideal increases contributions unless $g_{i}<\frac{1}{2} g_{i}^{*}$ initially, in which case an increase in $g_{i}^{*}$ leads to a discouragement effect: the ideal becomes increasingly out of reach, to the extent that it seems less attractive even to try reaching it.

For specifications of the type $f^{I I I+k}\left(g_{i}, g_{i}^{*}\right)=\left\{f^{j}\left(g_{i}, g_{i}^{*}\right)\right.$ when $g_{i} \leq g_{i}^{*}$, and 0 when $\left.g_{i}>g_{i}^{*}\right\}$, results are similar, except that all derivatives, including the cross derivative, equal zero whenever $g_{i}>g_{i}^{*}$. Thus, for $f^{I V}\left(g_{i}, g_{i}^{*}\right)$ (corresponding to eq. (7)) and $f^{V}\left(g_{i}, g_{i}^{*}\right)$, contributions are weakly increasing in $g_{i}^{*}$. For $f^{V I}\left(g_{i}, g_{i}^{*}\right)$, the cross derivative is positive if $g_{i}^{*}>g_{i}>\frac{1}{2} g_{i}^{*}$; hence contributions are strictly decreasing in $g_{i}^{*}$ when $g_{i} \in\left[0, \frac{1}{2} g_{i}^{*}\right\rangle$, strictly increasing in $g_{i}^{*}$ when $g_{i} \in\left[\frac{1}{2} g_{i}^{*}, g_{i}^{*}\right\rangle$, and unaffected by $g_{i}^{*}$ whenever $g_{i} \in\left[g_{i}^{*}, \infty\right\rangle$.

\section{B Proofs}

\section{Proof of Proposition 1:}

Proof. a) Consider first the case where the initial solution is interior. From (12), inserting from (2), we have

$$
g_{i}(m \beta)=g^{*}(m \beta)-\frac{u^{\prime}\left(F-g_{i}(m \beta)\right)}{2 a}
$$


where the actual contribution is written as a function of its social value. Differentiating this with respect to $m \beta$, using (10), we get

$$
\frac{d g_{i}}{d(m \beta)}=\frac{2 a}{-u^{\prime \prime}\left(2 a-u^{\prime \prime}\right)}>0
$$

If the initial contribution is zero, contributions will increase if and only if the change implies that (13) ceases to hold; otherwise $g_{i}$ is unchanged. We know from eq. (10) that $g_{i}^{*}$ is strictly increasing in $m \beta$ unless $m \beta<u^{\prime}(F)$. If $m \beta<u^{\prime}(F)$, however, (13) holds with strict equality. If, initially, (13) holds with strict inequality, the inequality will still hold after an incremental increase in $m \beta$, so contributions will stay unchanged at zero. If the individual is initially indifferent between contributing and not contributing, that is, if $a\left[g^{*}(m \beta)^{2}-\right.$ $\left.\left(g_{i}-g^{*}(m \beta)\right)^{2}\right]=u(F)-u\left(F-g_{i}\right)$ for some strictly positive $g_{i}$, a marginal increase in $m \beta$ will make contributing strictly preferable and the individual will go from $g_{i}=0$ to $g_{i}>0$, so in this case the increase in $g_{i}$ is strict.

b) For an interior solution, the change in utility due to a marginal change in $m \beta$ is given by

$$
\begin{aligned}
\frac{d U_{i}}{d(m \beta)} & =-u^{\prime} \frac{d g_{i}}{d(m \beta)}-2 a\left(g_{i}-g^{*}(m \beta)\left(\frac{d g_{i}}{d(m \beta)}-\frac{d g_{i}^{*}}{d(m \beta)}\right)\right. \\
& =\frac{d g_{i}}{d(m \beta)}\left[-u^{\prime}-2 a\left(g_{i}-g^{*}(m \beta)\right]+2 a\left(g_{i}-g^{*}(m \beta)\right) \frac{d g_{i}^{*}}{d(m \beta)}\right. \\
& =\frac{2 a\left(g_{i}-g^{*}(m \beta)\right)}{-u^{\prime \prime}}<0
\end{aligned}
$$

where the last line is obtained by using (11) and (10). We know from (12) that $g_{i}-g^{*}(m \beta)<0$; hence the sign of $d U_{i} / d(m \beta)$ is unambiguously negative.

For an initial corner solution $g_{i}=0$, we have that $U_{i}=u(F)-a\left(g^{*}(m \beta)\right)^{2}$ initially. Then,

$$
\frac{d U_{i}}{d(m \beta)}=-2 a\left(g^{*}(m \beta)\right) \frac{d g_{i}^{*}}{d(m \beta)} \leq 0
$$

We know from (8) and (10) that whenever $m \beta \leq u^{\prime}(F), g^{*}(m \beta)=0$, while whenever $m \beta \geq u^{\prime}(F), d g_{i}^{*} / d(m \beta)=1 /-u^{\prime \prime}>0$. Thus, $d U_{i} / d(m \beta)=0$ if and only if $m \beta \leq u^{\prime}(F)$. When $m \beta>u^{\prime}(F), g^{*}(m \beta)>0$ and $d g_{i}^{*} / d(m \beta)$, and utility is strictly decreasing when $m \beta$ increases.

\section{Proof of claim given in Footnote 17:}

Proof. The expected utility increase due to a decrease in beliefs $B_{i}$ may differ in magnitude from the expected utility decrease due to an equally large increase in $B_{i}$. For example, if utility were linear in $m \beta$ and $h(m \beta)$ were a symmetrical distribution, the individual would be indifferent to costless information; if utility were concave in $m \beta$, or if it were linear and $h(m \beta)$ had a thick upper tail, the individual would be willing to pay to avoid information, and if utility were convex and $h(m \beta)$ were symmetrical, the individual would prefer to get costless information. However, the curvature of $U_{i}$ as a function of $m \beta$ is indeterminate, 
unless one makes more specific assumptions about $u\left(x_{i}\right)$. Using (34), we find $d^{2} U_{i} / d(m \beta)^{2}$ by differentiation:

$$
\frac{d^{2} U_{i}}{d(m \beta)^{2}}=\frac{2 a}{\left(u^{\prime \prime}\right)^{2}}\left[\frac{-\left(u^{\prime \prime}\right)^{2}-2 a\left(g_{i}-g^{*}(m \beta)\right) u^{\prime \prime \prime}}{-u^{\prime \prime}\left(2 a-u^{\prime \prime}\right)}\right]
$$

The sign of this expression is given by the sign of $\left[-\left(u^{\prime \prime}\right)^{2}-2 a\left(g_{i}-g^{*}(m \beta)\right) u^{\prime \prime \prime}\right]$. Hence, $U_{i}$ is strictly concave in $m \beta$ if $\left[-\left(u^{\prime \prime}\right)^{2}-2 a\left(g_{i}-g^{*}(m \beta)\right) u^{\prime \prime \prime}\right]<0$ (which always holds if $\left.u^{\prime \prime \prime} \leq 0\right)$, but general conclusions cannot be drawn.

\section{Proof of Proposition 3:}

Proof. a) Differentiating (22) wrt $m \beta$ yields

$$
\begin{gathered}
-u^{\prime \prime} \frac{d g_{i}}{d(m \beta)}=(m \beta)^{2} \mu^{\prime \prime}\left(m \beta g_{i}\right) \frac{d g_{i}}{d(m \beta)}+\mu^{\prime}\left(m \beta g_{i}\right) \\
\frac{d g_{i}}{d(m \beta)}=\frac{\mu^{\prime}}{\left(-u^{\prime \prime}-(m \beta)^{2} \mu^{\prime \prime}\right)}>0
\end{gathered}
$$

Hence, if the initial solution is interior, $g_{i}$ is strictly increasing in $m \beta$. If the initial solution is not interior, i.e. $g_{i}=0$ initially, we know that $u^{\prime}(F) \geq$ $m \beta \mu^{\prime}$ initially. First, if $u^{\prime}(F)=m \beta \mu^{\prime}$ initially, a marginal change in $m \beta$ to $(m \beta)^{+}>m \beta$, all else given, must imply that $u^{\prime}(F)<(m \beta)^{+} \mu^{\prime}$, implying that after the change, the individual will make a strictly positive contribution. Hence, in this case an increase in $m \beta$ strictly increases contributions. Secondly, if $u^{\prime}(F)>m \beta \mu^{\prime}$ initially and $m \beta$ increases incrementally, say, to $(m \beta)^{++}$, we will have $u^{\prime}(F) \geq m \beta^{++} \mu^{\prime}$ and the contribution will be unaffected, that is, it will stay at zero.

b) Utility can be written as

$$
U_{i}^{C}=u\left(F-g_{i}\right)+\mu\left(m \beta g_{i}\right)
$$

Differentiating this with respect to $m \beta$, taking into account that $g_{i}$ is a function of $m \beta$, yields

$$
\begin{aligned}
\frac{d U_{i}^{C}}{d(m \beta)} & =-u^{\prime} \frac{d g_{i}}{d(m \beta)}+\left[g_{i}+m \beta \frac{d g_{i}}{d(m \beta)}\right] \mu^{\prime}\left(m \beta g_{i}\right) \\
& =\frac{d g_{i}}{d(m \beta)}\left[m \beta \mu^{\prime}-u^{\prime}\right]+g_{i} \mu^{\prime}
\end{aligned}
$$

Inserting from (22), this yields

$$
\frac{d U_{i}^{C}}{d(m \beta)}=g_{i} \mu^{\prime}>0
$$

for an interior solution. If $g_{i}=0$ initially and $u^{\prime}(F)=m \beta \mu^{\prime}$, then $d g_{i} /(m \beta)>0$, so in this case too, utility is strictly increasing in $m \beta$. Finally, if $g_{i}=0$ and $u^{\prime}(F)>m \beta \mu^{\prime}$ initially, we know from above that $d g_{i} / d(m \beta)=0$. In this case 
nothing changes; contributions are unchanged, hence self-image is unchanged, and utility is unchanged. Hence, in this case, $d U_{i}^{C} / d(m \beta)=0$.

The curvature of $U_{i}$ as a function of $m \beta$ cannot be unambiguously determined:

$$
\begin{aligned}
\frac{d^{2} U_{i}^{C}}{d(m \beta)^{2}} & =\frac{d g_{i}}{d(m \beta)} \mu^{\prime}+g_{i}\left(g_{i}+m \beta \frac{d g_{i}}{d(m \beta)}\right) \mu^{\prime \prime} \\
& =\frac{d g_{i}}{d(m \beta)}\left[\mu^{\prime}+g_{i} m \beta \mu^{\prime \prime}\right]+\left(g_{i}^{2}\right) \mu^{\prime \prime} \\
\frac{\mu^{\prime}\left[\mu^{\prime}+g_{i} m \beta \mu^{\prime \prime}\right]}{\left(-u^{\prime \prime}-(m \beta)^{2} \mu^{\prime \prime}\right)}+\left(g_{i}^{2}\right) \mu^{\prime \prime} & \lessgtr 0
\end{aligned}
$$

